\title{
Total energy expenditure in stable patients with cystic fibrosis.
}

Citation for published version (APA):

McCloskey, M., Redmond, A. O. B., Pyper, S., McCabe, C., Westerterp, K. R., \& Elborn, J. S. (2001). Total energy expenditure in stable patients with cystic fibrosis. Clinical Nutrition, 20, 235-241. https://doi.org/10.1054/clnu.2001.0389

Document status and date:

Published: 01/01/2001

DOI:

10.1054/clnu.2001.0389

Document Version:

Publisher's PDF, also known as Version of record

Document license:

Taverne

Please check the document version of this publication:

- A submitted manuscript is the version of the article upon submission and before peer-review. There can be important differences between the submitted version and the official published version of record.

People interested in the research are advised to contact the author for the final version of the publication, or visit the DOI to the publisher's website.

- The final author version and the galley proof are versions of the publication after peer review.

- The final published version features the final layout of the paper including the volume, issue and page numbers.

Link to publication

\footnotetext{
General rights rights.

- You may freely distribute the URL identifying the publication in the public portal. please follow below link for the End User Agreement:

www.umlib.nl/taverne-license

Take down policy

If you believe that this document breaches copyright please contact us at:

repository@maastrichtuniversity.nl

providing details and we will investigate your claim.
}

Copyright and moral rights for the publications made accessible in the public portal are retained by the authors and/or other copyright owners and it is a condition of accessing publications that users recognise and abide by the legal requirements associated with these

- Users may download and print one copy of any publication from the public portal for the purpose of private study or research.

- You may not further distribute the material or use it for any profit-making activity or commercial gain

If the publication is distributed under the terms of Article $25 \mathrm{fa}$ of the Dutch Copyright Act, indicated by the "Taverne" license above, 


\title{
Total energy expenditure in stable patients with cystic fibrosis
}

\author{
M. McCLOSKEY,* A.O.B. REDMOND,* S. PYPER,* C. McCABE,* K. R.WESTERTERP, J. S. ELBORN* \\ *Adult and Paediatric Cystic Fibrosis Centres Belfast City Hospital and Royal Belfast Hospital for Sick Children, Belfast, \\ Northern Ireland, ’ Department of Human Biology, Maastricht, The Netherlands (Correspondence to: MM, Adult CF centre, \\ Belfast City Hospital, Lisburn Road, Belfast, N. Ireland)
}

\begin{abstract}
Background and aims: Undernutrition is a common problem in patients with cystic fibrosis and is associated with a poor prognosis. The two aims of this study were to assess and compare the two main field techniques in the measurement of total energy expenditure and, secondly, to assess total energy expenditure in stable patients and compare with healthy controls.

Methods: Resting energy expenditure was measured using indirect calorimetry and total energy expenditure was measured using 24 -h heart rate (HR) methodology and doubly isotopically labelled water.

Results: Seventeen patients, mean age 23 years and $\mathrm{FEV}_{1} 52 \%$ predicted and thirteen controls were recruited. Resting energy expenditure was higher in patients $0.24(0.03) \mathrm{MJ} / \mathrm{kg}$ Fat-Free Mass (FFM) compared to controls $0.22(0.02)$ $\mathrm{MJ} / \mathrm{kg}$ FFM, $P=0.02$. Twenty-four hour heart rate underestimated total energy expenditure, $9.49(1.85) \mathrm{MJ} /$ day in patients compared to 11.69 (2.79) $\mathrm{MJ} /$ day using doubly labelled water. There was no difference in total energy expenditure in patients and controls using both methods, 11.69 (2.79) $\mathrm{MJ} /$ day compared to 11.38 (2.71) $\mathrm{MJ} /$ day using doubly isotopically labelled water.

Conc/usions: In clinically stable young adult patients with moderately severe respiratory disease total energy expenditure is comparable to that an a control population despite in increase in resting energy expenditure and both 24-h HR and doubly isotopically labelled water are suitable for use in patients with cystic fibrosis. (c) 2001 Harcourt Publishers Ltd.
\end{abstract}

Key words: cystic fibrosis; energy expenditure

\section{Introduction}

Survival for patients with cystic fibrosis (CF) has improved since the condition was first described in 1938 , when it was usually a post-mortem diagnosis in affected babies (1). It is estimated now that the median survival for children in the UK born in the 1990s is 40 years (2). This improved survival has been attributed to a number of factors including early diagnosis, aggressive physiotherapy, potent antibiotic therapy and the development of CF centres $(3,4)$. Nutritional status has also been identified as an important prognositic factor $(5,6)$.

Undernutrition, however, remains a problem in many patients with CF. Recent studies have shown that patients with CF still have height and weight indices below the mean for the population (7-9). This implies an imbalance between energy intake and total energy expenditure (TEE), but the causes of this imbalance in $\mathrm{CF}$ are unclear. TEE is composed of resting energy expenditure (REE), dietary induced thermogenesis and physical activity. REE, which comprises about $70 \%$ of TEE is elevated in CF, but very little is known about
TEE in patients. The only previous study to measure TEE in adolescents found that it was similar in a stable population of patients with $\mathrm{CF}$ to an age and sex matched control group. TEE was measured by 24-h heart rate (HR) methodology (24-h HR) (10). Other studies have measured TEE in infants and children with CF. Shepherd et al. assessed TEE in clinically stable infants with CF using doubly labelled water (DLW) and found that in infants with CF, TEE was increased compared to a control population (11). Tomezsko et al. measured TEE in pre-pubertal children using DLW and found TEE to be increased in those children who were $\Delta \mathrm{F} 508$ homozygotes compared to a control population (12). However, other studies have found that TEE in infants and pre-pubertal children with $\mathrm{CF}$ is not different compared to control populations (13). These conflicting results may reflect a difference due to the markedly different ages of the populations studied or it may reflect a methodological problem as different field techniques were used in these various studies.

In this study TEE was measured in a group of stable young adults with CF using two independent techniques. DLW and 24-h HR are the most commonly used field techniques for the measurement of TEE, however, although both techniques have been extensively validated in normal populations, there are no studies 
comparing the two techniques in patients with $\mathrm{CF}$ (14-17). The aim of this study was to assess repeatability of 24-h HR methodology for use in patients with CF and compare DLW and 24-h HR in the assessment of TEE in a stable population of young adult patients with $\mathrm{CF}$.

\section{Methods}

Seventeen patients with CF who were clinically stable and 13 age, sex and weight matched controls were studied. The study period was 2 weeks. Patients with moderately severe lung disease, $30 \%<\mathrm{FEV}_{1}<70 \%$ were invited to participate in the study and were considered to be clinically stable if their $\mathrm{FEV}_{1}$ was within $5 \%$ of their best over the previous 6 months, they were not on antibiotics and had no symptoms suggestive of an exacerbation of respiratory symptoms. All patients were taking pancreatic enzyme supplements, oral vitamin supplements and some took inhaled bronchodilator therapy. Controls were on no medication and had no intercurrent illnesses. The study was approved by the local ethics committee.

On the first day of the study subjects came to the investigation room between 08:00 and 09:30 having fasted from midnight. Patients had taken their morning medication apart from nebulized or inhaled beta agonists.

\section{REE and TEE (24-h HR) measurements}

REE was measured by open circuit indirect calorimetry using a Quinton Qplex machine with a face mask. A preliminary study had been undertaken to compare REE measurements using both a face mask and mouth piece with the Quinton Qplex. There was no difference in REE measurements using both methods, but patients and controls prefered the face mask as it was more comfortable. A face mask was therefore used in all subjects for the measurement of gas exchange. After an acclimatization period of $20 \mathrm{~min}$, gas exchange measurements were recorded each minute for a further $20 \mathrm{~min}$. All subjects had visited the investigation room on one previous occasion when they had been familiarized with the equipment. Subjects then had a rest period of 30 min. Individual heart rate oxygen consumption curves were then calibrated for each subject as described previously (16-19). Subjects sat for $6 \mathrm{~min}$, stood for 6 min and walked on a treadmill at two different work loads for $6 \mathrm{~min}$ each. Most patients and all of the controls walked at a speed of $2.7 \mathrm{~km} / \mathrm{h}$ and a gradient of $5 \%$ followed by a speed of $4 \mathrm{~km} / \mathrm{h}$ and a gradient of $10 \%$. Patients not able to exercise at these limits had been identified at the initial familiarization visit. These patients walked for $6 \mathrm{~min}$ at $2 \mathrm{~km} / \mathrm{h}$ at a zero gradient followed by $2.7 \mathrm{~km} / \mathrm{h}$ at a zero gradient. After an initial calibration period readings of heart rate and gas exchange were recorded each minute for the last $3 \mathrm{~min}$ of each period. After the exercise period heart rate monitors (Polar Sports Tester, Kempele, Finland) were then attached to the subjects with instructions to take them of as they were going to bed to sleep that night.

\section{TEE (DLW) measurements}

Subjects were then given a previously weighted dose of DLW which contained $0.15 \mathrm{~g} / \mathrm{kg}$ body water ${ }^{2} \mathrm{H}_{2} \mathrm{O}$ and $0.30 \mathrm{~g} / \mathrm{kg}$ body water $\mathrm{H}_{2} \mathrm{O}^{18}$. The Maastricht protocol for the measurement of TEE using DLW was used in this study (20) and subjects were instructed to drink the contents at 22:00 on day zero and after overnight equilibration, collect urine samples on days one, eight and fifteen, the second voiding of the morning and the last voiding at night in all cases. Subjects returned to the examination room between day eight and day 14 and had their REE measured again and underwent repeat calibration for heart rate oxygen consumption curves. Subjects wore the heart rate monitor as on day zero. All urine samples were recovered by the examiner the day after collection.

Fat-free mass (FFM) was estimated from the first urine sample on day one as described previously (20). REE was calculated using the equation of Elia and Livesey (21). Total energy expenditure was calculated from the rate of disappearance of this isotopes as described previously $(20,22)$. Data from the heart rate monitors was converted into oxygen consumption and indirectly energy expenditure from each persons calibration curves.

\section{Statistical analysis}

Statistical analysis of repeatability of measurements of TEE using 24-h HR methodology was by the method of Bland and Altman (23). Comparison between patients and controls was by non-parametric Mann-Whitney U-testing. Agreement between the two methods for assessing TEE was assessed by the method of Bland and Altman. REE measurements were expressed in $\mathrm{MJ} / \mathrm{kg}$ FFM and \% predicted according to the equations of Schofield (24). TEE was expressed in $\mathrm{MJ} /$ day.

\section{Ethical approval}

This study was approved by the ethical committee of Queens University of Belfast and all subjects gave written, informed consent to participating in the study.

\section{Results}

The patients with $\mathrm{CF}$ had lower weight, BMI and lung function compared to controls. The mean $\%$ predicted 
$\mathrm{FEV}_{1}$ of the CF population was $52(12) \%$. The percent FFM was significantly higher in the CF study group compared to the control population, $59.2(11.2) \%$ and $55.5(5.8) \%, P=0.04$ (Table 1).

Resting energy expenditure was higher in patients, $0.24(0.03) \mathrm{MJ} / \mathrm{Kg}$ FFM compared to controls, 0.22 $(0.02) \mathrm{MJ} / \mathrm{kg}$ FFM, $P=0.02$. When REE was expressed as $\%$ predicted from the equations of Schofield, mean $\%$ predicted REE in patients was 127.4 (14. 1)\% compared to $113.4(12.3) \%$ in controls, $P=0.04$. The coefficients of variation for repeated measurements of REE were $7.9 \%$ in patients and $12.6 \%$ in controls.

There was no statistical difference in TEE in patients and controls using 24-h HR methodology, 9.49 (1.85) $\mathrm{MJ} /$ day in patients and 9.84 (2.07) $\mathrm{MJ} /$ day in controls, (Table 2). When TEE measurements were expressed per $\mathrm{kg}$ of body weight and per $\mathrm{kg}$ of FFM there was still no difference between patients and controls. All subjects

Table 1 Clinical data of patients and controls

\begin{tabular}{lccc}
\hline & CF subjects & Controls & $P$-value \\
\hline Number & 17 & 13 & \\
Sex M/F & $10 \mathrm{M} / 7 \mathrm{~F}$ & $7 \mathrm{M} / 6 \mathrm{~F}$ & \\
Weight $(\mathrm{kg})$ & $53.0(11.0)$ & $63.0(12.5)$ & 0.09 \\
Height $(\mathrm{cm})$ & $166.0(7.9)$ & $167.0(8.27)$ & $\mathrm{NS}$ \\
BMI $\left(\mathrm{kg} / \mathrm{m}^{2}\right)$ & $19.1(3.1)$ & $21.8(3.0)$ & 0.004 \\
FFM $(\mathrm{kg})$ & $31.1(5.9)$ & $32.6(6.8)$ & $\mathrm{NS}$ \\
$\%$ FFM & $62.9(4.3) \mathrm{M}$ & $57.7(7.2) \mathrm{M}$ & \\
& $54.6(2.7) \mathrm{F}$ & $54.5(4.7) \mathrm{F}$ & 0.04 \\
FEV $_{1}(\%$ predicted $)$ & $52.0(12.0)$ & $103.0(4.0)$ & $<0.001$ \\
\hline
\end{tabular}

Values are means (standard deviation) BMI: body mass index; FFM: fat-free mass estimated by deuteurium dilution; \% FFM: per cent body weight that is fat free; NS: non-significant $P$-value. kept the HR monitors on during their waking hours from about 11:00 until going to bed. All subjects had at least 2 separate days when they wore the HR monitor and six patients and five controls had 3 days. The error standard deviation for repeated measurements of TEE using 24-h HR methodology was $0.02 \mathrm{MJ} / \mathrm{kg} /$ day in patients and $0.02 \mathrm{MJ} / \mathrm{kg} /$ day in controls giving coefficients of variation of $10 \%$ in patients and $10.5 \%$ in controls.

Eleven patients and 10 controls had TEE measured by DLW in addition to 24-h HR methodology. There was no significant difference in TEE between patients and controls using DLW methodology, 11.69 (2.79) MJ/day in patients compared to 11.38 (2.71) $\mathrm{MJ}$ /day in controls. When TEE was expressed as MJ per kg FFM controls had a higher energy expenditure, $P<0.05$ (Table 2). TEE values by DLW were higher than 24-h HR values, mean \% difference in patients being $8.8(7.9) \%$ and in controls mean \% difference between the two methods was $5.2(5.9) \%$. Comparing the two techniques using the method of Bland and Altman, all but one of the values were within two standard deviations of the mean difference between the methods in patients and similarly in controls.

There was a positive correlation between REE and TEE using both HR and DLW methodologies in patients and controls, the DLW data are shown in Figs 1 and 2. Using HR methodology, TEE $=0.9$ $\mathrm{REE}+9, r=0.9, P=0.008$ in patients and $\mathrm{TEE}=0.8$ $\mathrm{REE}+95.7, r=0.7, P=0.006$ in controls.

There was no correlation between TEE and $\mathrm{FEV}_{1}$ in patients $(r=0.15, \quad P=0.7)$ or between TEE and FFM in patients $(r=0.09, P=0.8)$, but

Table 2 TEE measurements using 24-h HR and DLW in patients and controls

\begin{tabular}{|c|c|c|c|c|c|c|c|c|}
\hline \multirow[b]{3}{*}{$\begin{array}{l}\text { Subject } \\
\text { number }\end{array}$} & \multicolumn{4}{|c|}{ TEE using 24-h HR } & \multicolumn{4}{|c|}{ TEE using DLW } \\
\hline & \multicolumn{2}{|c|}{ CF subjects } & \multicolumn{2}{|c|}{ Controls } & \multicolumn{2}{|c|}{ CF subjects } & \multicolumn{2}{|c|}{ Controls } \\
\hline & $\begin{array}{c}\text { mean } \\
\mathrm{MJ} / \text { day }\end{array}$ & $\begin{array}{c}\text { mean } \\
\mathrm{MJ} / \mathrm{kg} \mathrm{FFM} / \text { day }\end{array}$ & $\begin{array}{l}\text { mean } \\
\mathrm{MJ} / \text { day }\end{array}$ & $\begin{array}{c}\text { mean } \\
\mathrm{MJ} / \mathrm{kg} \mathrm{FFM} / \\
\text { day }\end{array}$ & $\begin{array}{l}\text { mean } \\
\mathrm{MJ} / \text { day }\end{array}$ & $\begin{array}{c}\text { mean } \\
\mathrm{MJ} / \mathrm{kg} \mathrm{FFM} / \\
\text { day }\end{array}$ & $\begin{array}{c}\text { mean } \\
\mathrm{MJ} / \text { day }\end{array}$ & $\begin{array}{c}\text { mean } \\
\mathrm{MJ} / \mathrm{kg} \mathrm{FFM} / \\
\text { day }\end{array}$ \\
\hline 1 & 8.74 & 0.20 & 10.30 & 0.25 & 12.00 & 0.34 & 11.46 & 0.37 \\
\hline 2 & 10.39 & 0.23 & 10.92 & 0.21 & 10.33 & 0.24 & 11.46 & 0.31 \\
\hline 3 & 8.48 & 0.25 & 11.23 & 0.24 & 7.98 & 0.24 & 11.52 & 0.44 \\
\hline 4 & 7.70 & 0.17 & 10.01 & 0.17 & 8.62 & 0.23 & 7.57 & 0.29 \\
\hline 5 & 10.52 & 0.25 & 6.72 & 0.19 & 11.71 & 0.29 & 15.54 & 0.33 \\
\hline 6 & 11.55 & 0.16 & 11.81 & 0.19 & 16.27 & 0.27 & 7.03 & 0.29 \\
\hline 7 & 10.02 & 0.23 & 14.53 & 0.23 & 10.32 & 0.28 & 10.92 & 0.38 \\
\hline 8 & 7.55 & 0.15 & 9.54 & 0.21 & 11.07 & 0.23 & 10.46 & 0.42 \\
\hline 9 & 10.28 & 0.19 & 7.13 & 0.24 & 13.39 & 0.26 & 10.59 & 0.32 \\
\hline 10 & 6.05 & 0.24 & 8.41 & 0.21 & 8.16 & 0.28 & 11.21 & 0.32 \\
\hline 11 & 9.25 & 0.22 & 10.22 & 0.29 & 11.88 & 0.29 & & \\
\hline 12 & 9.31 & 0.17 & 8.79 & 0.19 & & & & \\
\hline 13 & 10.05 & 0.17 & 8.49 & 0.21 & & & & \\
\hline 14 & 8.35 & 0.20 & & & & & & \\
\hline 15 & 10.84 & 0.18 & & & & & & \\
\hline 16 & 14.19 & 0.17 & & & & & & \\
\hline 17 & 8.20 & 0.19 & & & & & & \\
\hline mean & 9.49 & 0.20 & 9.84 & 0.22 & 11.69 & 0.27 & 11.38 & 0.35 \\
\hline SD & 1.85 & 0.03 & 2.07 & 0.03 & 2.79 & 0.04 & 2.71 & 0.05 \\
\hline
\end{tabular}




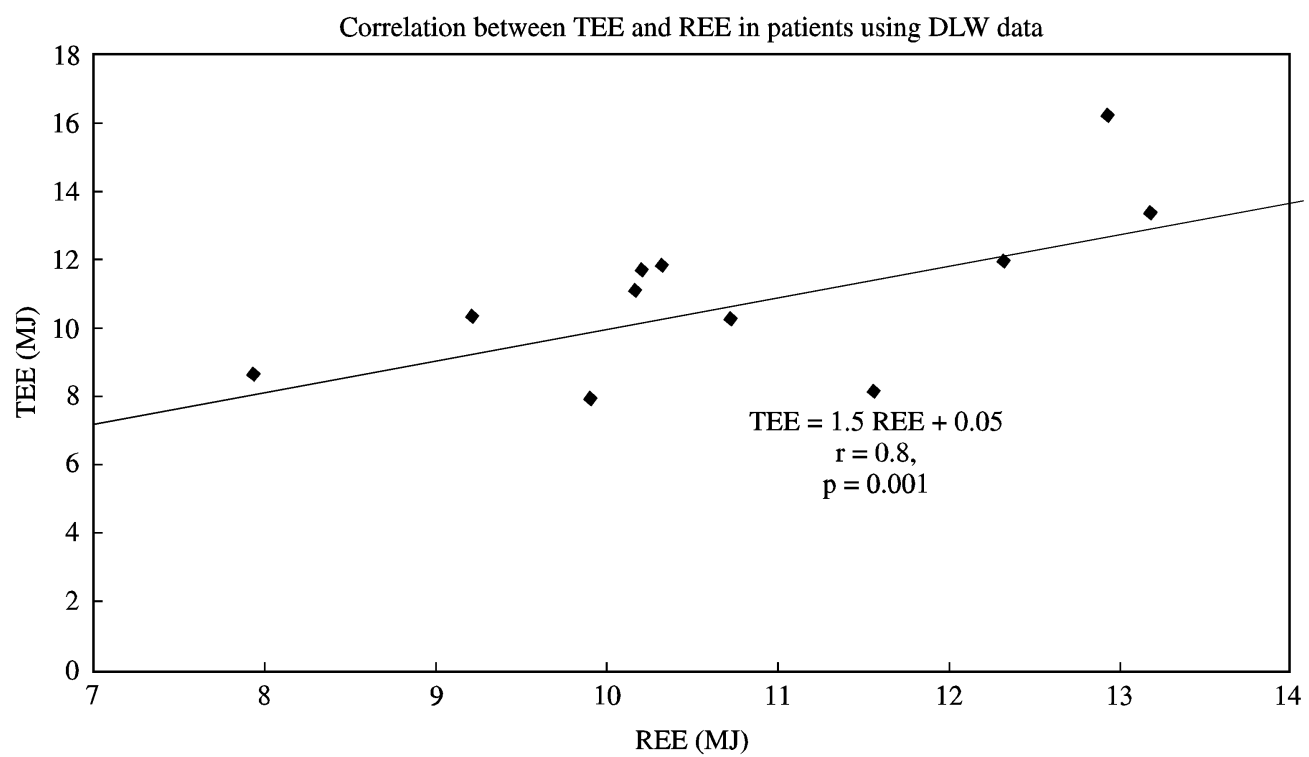

Fig. 1 Correlation between TEE and REE in patients using doubly labelled water (DLW) data. There is a positive correlation between REE and TEE in patients using both 24-h heart rate methodology and doubly isotopically labelled water, the DLW data are shown.

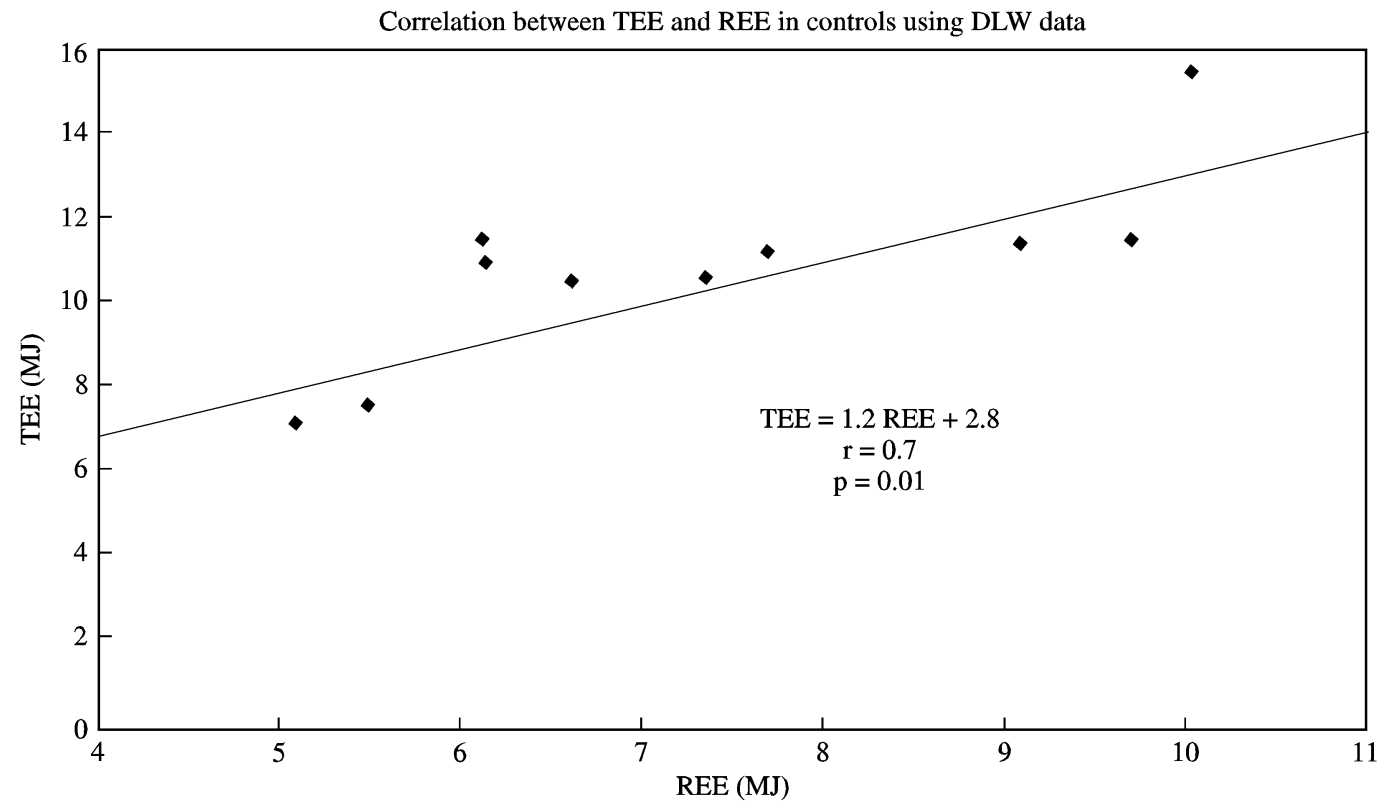

Fig. 2 Correlation between TEE and REE in controls using doubly labelled water (DLW) data. There is a positive correlation between REE and TEE in controls using both 24-h heart rate methodology and doubly isotopically labelled water, the DLW data are shown.

there was a positive correlation in controls $(r=0.8$, $P=0.003)$.

Resting heart rate was higher in patients, 83(7) BPM, compared to 72(10) BPM in controls $(P<0.003)$. Flex heart rate also tended to be higher in patients, 100(8) BPM compared to 96(8) BPM, this was not statistically significant $(P=0.09)$.

Mean physical activity levels or non-resting energy expenditure as measured by TEE/REE was higher in the control group compared to the patient group using both DLW and 24-h HR values for TEE. Using the 24-h HR values for TEE, PAL in patients was 1.2(0.1) compared to $1.3(0.1)$ in controls $(P=0.07)$, and using the DLW data PAL was 1.6(0.1) in patients and 1.7(0.1) in controls $(P=0.08)$. There was no correlation between PAL and FFM in patients or controls $(r=0.04$ and $r=-0.05$ respectively). There was also no correlation between PAL and REE in either patients or controls $(r=0.6$ and $r=0.2$ respectively).

\section{Discussion}

This study shows that TEE was not elevated in a young adult population with $\mathrm{CF}$ with stable symptoms 
compared to a control population and that 24-h HR underestimated TEE in both patients and controls when compared to DLW.

Employing the two commonly used field techniques there was no statistical difference between TEE in stable patients and controls. When results were expressed in $\mathrm{MJ} /$ day and $\mathrm{MJ} / \mathrm{kg}$ body weight there was no difference in TEE between patients and controls, but when expressed in $\mathrm{MJ} / \mathrm{kg}$ FFM there was a trend for TEE to be higher in controls. These findings are in agreement with the study by Spicher et al. who used 24-h HR methodology alone (10). Other conflicting studies relating to TEE in patients with $\mathrm{CF}$ are partly explained by whether results are expressed per $\mathrm{kg}$ body weight or per kg FFM. The increase in TEE noted by Shepherd et al. in pre symptomatic babies is less apparent when differences in body composition are accounted for between patients and controls (11).

Patients with $\mathrm{CF}$ have a lower fat mass and greater \% FFM than control populations $(25,26)$. In this study there was no correlation between FFM and TEE within the $\mathrm{CF}$ population, but that there was a positive correlation between FFM and TEE within the control population. It is difficult to draw clear conclusions from this in that the relationship between FFM and TEE within control populations is variable within the reported studies and the numbers in this study were relatively small $(27,28)$. There are no data on the relationship between FFM and TEE within the CF population in the literature. A further study with larger numbers within this adolescent age group would be informative.

The other variable in the studies measuring TEE in patients with $\mathrm{CF}$ is age. Shepherd et al. assessed TEE in infants (11), Tomezsko et al. measured TEE in pre pubertal children (12) and the patients in the study by Spicher et al. included pre-pubertal children and young adolescents (10). Besides differences in growth rates between these different age groups, there are also differences in physical activity which may partly explain the differing results in these studies. Physical activity levels in infants are generally quite uniform, whereas even in adults without any chronic disease there is a huge variation in physical activity (29). When one takes into account the additional factor of decreasing pulmonary function in patients with $\mathrm{CF}$, which has been shown to decrease physical activity then the variation of physical activity within the CF population may be even greater than in healthy adults (30).

This study supports the findings of Spicher et al. in that PAL was significantly decreased in the patients compared to healthy controls. The patients in this study had more severe lung disease than those in the study by Spicher, where the mean $\mathrm{FEV}_{1}$ was $63(5) \%$ predicted and in this present study mean $\mathrm{FEV}_{1}$ was $52(12) \%$. The present study did not find a correlation between TEE and $\mathrm{FEV}_{1}$, but the question remains regarding TEE in patients with severe pulmonary disease. One would expect that in these patients physical activity is decreased even further and it is possible that there is a compensatory increase in the work of breathing in this group which counteracts this.

The REE measurements in this study were higher than predicted even in the control group. This may be due to methodological issues in that subjects came to the investigation room on the morning of the study from home, therefore the REE measurements were not true basal energy expenditure measurements. However, patients and controls were all taken directly to the investigation room so the error was minimized. This may also explain the relatively low PAL even in the control group.

DWL and 24-h HR are the most commonly used field techniques for the measurement of TEE. DLW is an isotope dilution technique based on the differing rates of disappearance of ${ }^{2} \mathrm{H}$ and $\mathrm{O}^{18}$ from the body. ${ }^{2} \mathrm{H}$ labels the body water pool and $\mathrm{O}^{18}$ labels both the water and bicarbonate pools, and the different elimination rates give an estimate of carbon-dioxide production (20). The technique has been shown to have an accuracy of between 2 and $4 \%$ in control populations when compared to whole body indirect calorimetry $(17,22)$. It is also an expensive technique and the need for mass spectrometry for analysis limits its widespread use. In addition, although extensively validated in control populations the technique has not been validated against whole body indirect calorimery within the $\mathrm{CF}$ population and it is possible that the equilibration pools may differ within this population.

The twenty-four-hour HR methodology is much less expensive and is very easy to use. It is based on the principle that above a critical heart rate, the individually determined 'Flex HR', there is a linear relationship between oxygen consumption and heart rate $(16,18,19)$. When compared with DLW in control populations the technique has consistently underestimated TEE $(16,19)$. In this present study 24-h HR also underestimated TEE compared to DLW, but the results of the present study are similar to other studies in both the patient and control group (15). Although an exercise treadmill was used as the calibration procedure in this study, because all of the subjects were familiar with the type of equipment and had frequently used it on school visits to gymnasiums, it is very unlikely that the heart rate changes in these experimental situations can duplicate exactly the cardiorespiratory changes involved in spontaneous and free-living energy expenditure patterns. This will continue to be a problem with the 24-h HR methodology, but to some extent it can be minimalized by using an exercise procedure for calibration with which subjects are very familiar. In studies measuring energy expenditure in children, bicycle ergometry is sometimes used as children cycle quite a lot. In this study as in others, 24-h HR methodology may give errors in measurements in individual subjects, but gives reasonable group results within the $\mathrm{CF}$ 
population to the extent that it could be a very useful tool in assessing activity patterns in patients with varying degrees of respiratory disease (19).

The heart-rate methodology proved to be repeatable in patients and controls. Results were in keeping with other published studies assessing the repeatability of the method in healthy volunteers $(15,20,31)$. The 24-h HR method provided additional information regarding resting and flex heart rates in patients and controls. Resting heart rate levels were consistently elevated in the patient relative to the control group. This could be attributable to the catecholamine levels $(32,33)$, or increased work of breathing (34).

Patients and controls found both methods acceptable and non-intrusive and, although DLW has not been validated for use in this population, it does seem to be a valuable method for measuring TEE. Twenty-four-hour have HR is repeatable and provides valuable additional information on physical activity levels and is more acceptable to an adolescent population despite underestimating TEE, the technique is also economically more viable for widespread use than doubly isotopically labelled water.

In conclusion this study shows that TEE is not increased in a stable population of young adult patients with CF relative to a control population despite an increase in REE. They also have reduced activity levels compared to a control population. Twenty-four-hour HR methodology has also been shown to be a repeatable and reproducible method for the measurement of TEE in patients with $\mathrm{CF}$.

\section{Acknowledgements}

We would like to thank the CF Trust (UK) for supporting this research and Dr MBE Livingstone (University of Ulster, Coleraine, Northern Ireland) for her help and advice in the use of 24-h HR methodology.

\section{References}

1. Anderson D M. Cystic Fibrosis of the pancreas and its relation to celiac disease: a clinical and pathological study. Am J Dis Chil 1938; 56: 344-349

2. Elborn J S, Shale D J, Britton J R. Cystic Fibrosis: current survival and population estimates to the year 2000. Thorax 1991; 46: 881-885

3. Warwick W J. Prognosis for survival with cystic fibrosis: the effects of early diagnosis and cystic fibrosis centre care. Acta paediatrica Scandanavica 1982; 301(suppl): 27-31

4. Vic P, Ategbo S, Gottrand F et al. Nutritional impact of antipseudomonas antibiotic courses in cystic fibrosis. Arch Dis Chil 1997; 76: 437-440

5. Dodge J A, Morrison S, Lewis P A et al. Incidence, population and survival of cystic fibrosis in the UK, 1968-95. Arch Dis Chil 1997; 77: 493-496

6. Morrison S, Dodge J A, Cole T J et al. Height and weight in cystic fibrosis: a cross sectional study. Arch Dis Chil 1997; 77: 497-500

7. Winklhofer-Roob B M. Nutritional status in cystic fibrosis: where to go from here? Am J Clin Nutr 1998; 67: 817-818

8. Dodge $\mathbf{J}$ A, Morrison S, Lewis P A et al. Cystic Fibrosis in the UK 1968-1988: Incidence, population and survival. Paed and Perinatal Epidemiol 1993; 7: 157-166
9. Bell S C, Bowerman A R, Davies C A, Campbell I A, Shale D J, Elborn J S. Nutrition in adults with cystic fibroisis. Clin Nutr 1998; 17: 211-215

10. Spicher V, Roulet M, Schultz Y. Assessment of total energy expenditure in free-living patients with cystic fibrosis. J Pediatr 1991; 118: 865-872

11. Shepherd R W, Holt T L, Vasques-Valasquez L, Coward W A, Prentice A, Lucas A. Increased energy expenditure in young children with cystic fibrosis. Lancet 1988; 1300-1303

12. Tomezsko J L, Stallings V A, Kawchak D A, Goin J E, Diamond G, Scanlin T F. Energy expenditure and genotype of children with cystic fibrosis. Ped Res 1997; 35: 451-460

13. Durie P R, Pencharz P B. Nutrition in CF. Brit Med Bulletin 1992; 48: 823-847

14. Spurr G B, Prentice A M, Murgatroyd P R et al. Energy expenditure from minute by minute heart rate recording: comparison with indirect calorimetry. Am J Clin Nutr 1988; 48: $552-559$

15. Schulz S, Westerterp K, Bruck K. Comparison of energy expenditure by the doubly labeled water technique with energy intake, heart rate, and activity recording in man. Am J Clin Nutr 1989; 49: 1146-1154

16. Livingstone M B E, Prentice A M, Coward W A et al. Simultaneous measurement of free living energy expenditure by the doubly labeled water method and heart-rate monitoring. Am $\mathbf{J}$ Clin Nutr 1990; 52: 59-65

17. Murgatroyd P R, Shetty P S, Prentice A M. Techniques for the measurement of human energy expenditure: a practical guide. Internat J Obesity 1993; 17: 549-568

18. Christensen C C, Frey H M M, Foenstelien E, Eng E, Aadland E A, Refsum H E. A critical evaluation of energy expenditure estimates based on individual oxygen consumption/heart rate curves and average daily heart rate. Amer J Clin Nutr 1983; 37 : 468-472

19. Livingstone M B E, Coward W A, Prentice A M et al. Daily energy expenditure in free-living children: comparison of heartrate monitoring with the doubly labeled water method. Amer J Clin Nutr 1992; 56: 343-352

20. Westerterp K R, Wouters L, Van Marken lichtenbelt W D. The maastricht protocol for the measurement of body composition and energy expenditure with labeled water. Obesity Research 1995; 3 : $49-57$

21. Elia M, Livesey G. Energy expenditure and fuel selection in biological systems: the theory and practice of calculations based on indirect calorimetry and tracer methods. World Rev Nutr Diet 1992; 70: 68-131

22. Schoeller D A, Van Santen E. Measurement of energy expenditure in humans by doubly labeled water method. J Appl Physiol 1982; 53: 955-959

23. Bland J M, Altman D G. Statistical methods for assessing agreement between two methods of clinical measurement. Lancet 1986; $1: 307-310$

24. Schofield W N, Schofield C, James W P T. Predicting basal metabolic rate, new standards and review of previous work. Human nutrition. Clin Nutr 1985; 39C: 5-41

25. Greer R, Shepherd R, Cleghorn G, Bowling F G, Holt T. Evaluation of growth and changes in body composition following neonatal diagnosis of cystic fibrosis. J Pediatr Gastroent \& Nutr 1991; 13: $52-58$

26. Nir M, Lanng S, Johansen H K, Koch C. Long term survival and nutritional data in patients with cystic fibrosis treated in a Danish centre. Thorax 1996; 51: 1023-1027

27. Carpenter W H, Poehlman E T, O'Connell M, Goran M I. Influence of body composition and resting metabolic rate on variation in total energy expenditure: a meta analysis. Am J Clin Nutr 1995; 61: 4-10

28. Rush E C, Plank L D, Coward W A. Energy expenditure of young Polynesian and European women in New Zealand and relations to body composition. Am J Clin Nutr 1999; 69: 43-48

29. Westerterp K R, Meijer G A L, Janssen E M E, Saris W H M, Hoor F T. Long-term effect of physical activity on energy balance and body composition. Brit J Nutr 1992; 68: 21-30

30. Boucher G P, Lands L C, Hay J A, Hornby L. Activity levels and the relationship to lung function and nutritional status in children with cystic fibrosis. Am J Physical Med and Rehabilitation 1997; 76: $311-315$ 
31. Racette S B, Schoeller D A, Kushner R F. Comparison of heart rate and physical activity recall with doubly labeled water in obese women. Med \& Scie in Sports \& Exe 1995; 27: 126-133

32. Elborn J S, Cordon S M, Western P J, Macdonald I, Shale D J. Tumour necrosis factor-alpha, resting energy expenditure and cachexia in cystic fibrosis. Clin Science 1993; 85: $563-568$
33. Peckham D, Crouch S, Humphreys H, Lobo B, Tse A, Knox A J. Effect of antibiotic treatment on inflammatory markers and lung function in cystic fibrosis patients with pseudomonas cepacia. Thorax 1994; 49: 803-807

34. Bell S C, Saunders M J, Elborn J S, Shale D J. Resting energy expenditure and oxygen cost of breathing in patients with cystic fibrosis. Thorax 1996; 51: 126-131

Submission date: 21 July 2000 Accepted: 18 December 2000 Published online: 14 May 2001 